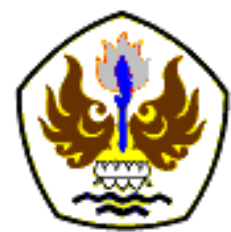

INFOMATEK

Volume 18 Nomor 2 Desember 2016

\title{
SISTEM PENCEGAHAN SERANGAN BRUTEFORCE PADA UBUNTU SERVER DENGAN MENGGUNAKAN FAIL2BAN
}

\author{
Iwan Kurniawan ${ }^{\star}$, Ferry Mulyanto, Fuad Nandiasa \\ Program Studi Teknik Informatika \\ Fakultas Teknik - Universitas Pasundan
}

\begin{abstract}
Abstrak: Perkembangan internet yang semakin cepat dengan berbagai macam fungsi dan kebutuhan, menuntut meningkatnya kualitas keamanan jaringan webserver. Terutama dengan semakin terbukanya pengetahuan hacking dan cracking, didukung dengan banyaknya tools yang tersedia dengan mudah dan kebanyakan free, semakin mempermudah para intruder dan attacker untuk melakukan aksi penyusupan ataupun serangan. Masalah timbul ketika sang administrator sedang tidak berada pada posisi siap sedia, misalnya sakit, berada di luar jam kerja, atau adanya kepentingan mendadak, sedangkan serangan terhadap server bisa terjadi kapan saja. Salah satu serangan yang berakibat fatal adalah, serangan bruteforce. Serangan bruteforce pada server memang jarang sekali terjadi, tetapi akibat yang ditimbulkan dari serangan ini adalah penyerang bisa mendapatkan hak akses administrator dan tentu saja membahayakan server. Administrator membutuhkan suatu sistem yang dapat membantu kerjanya. Sebuah sistem yang dapat memberikan hasil laporan apa yang terjadi pada sistem apakah itu sebuah serangan atau penyusupan. Dengan hasil laporan yang di dapat ,administrator akan bertindak lebih jauh untuk mencegah terjadinya serangan di masa yang akan datang.
\end{abstract}

Kata kunci: Bruteforce, Fail2ban

\section{PENDAHULUAN}

\subsection{Latar Belakang}

Perkembangan internet yang semakin cepat dengan berbagai macam fungsi dan kebutuhan, menuntut meningkatnya kualitas keamanan jaringan webserver. Terutama dengan semakin terbukanya pengetahuan hacking dan cracking, didukung dengan banyaknya tools yang tersedia dengan mudah dan kebanyakan free, semakin mempermudah para intruder dan attacker untuk melakukan aksi penyusupan ataupun

\footnotetext{
*) iwank@unpas.ac.id
}

serangan. Terjadi nya penyusupan atau serangan dapat mengakibatkan masalah pada keberlangsungan sistem yang diserang oleh attacker .

Pencegahaan yang paling sering dilakukan untuk masalah ini adalah dengan menempatkan seorang administrator. Masalah timbul ketika sang administrator sedang tidak berada pada posisi siap sedia, misalnya sakit, berada di luar jam kerja, atau adanya kepentingan mendadak.Sedangkan serangan terhadap server bisa terjadi kapan saja. 
Keamanan jaringan komputer mempunyai tiga basis yang harus terpenuhi yang disebut dengan The Security Trinity, yaitu prevention, detection dan response (Canavan [1]).

Maka, dari permasalahan tersebut, administrator membutuhkan suatu sistem yang dapat membantu kerjanya. Sebuah sistem yang dapat membantu administrator jika sedang tidak berada di tempat, sebuah sistem yang dapat memberikan hasil laporan apa yang terjadi pada sistem apakah itu sebuah serangan atau penyusupan. Dengan hasil laporan yang di dapat, administrator akan bertindak lebih jauh untuk mencegah terjadinya serangan di masa yang akan datang.

Di era yang modern ini, teknologi bukan merupakan hal yang baru terutama di perusahaan. Hampir semua perusahaan menggunakan teknologi dalam menjalankan, mengembangkan dan mendukung oprasional segala jenis perusahaan bisnis. Salah satunya persaingan bisnis di bidang peminjaman uang. Perbankan salah satu lembaga intermediasidalam negara, berkenaan hal tersebut bank menutut para karyawan dapat memberikan pelayanan yang terbaik dan memuaskan kepada nasabah-nasabah. Dari latar belakang di atas, perumusan masalah yakni bagaimana membangun sebuah sistem yang dapat memberikan notifikasi kepada admin jika terjadi serangan terhadap server.

\section{METODOLOGI}

Metodologi yang digunakan dalam penelitian ini adalah sebagai berikut:

1. Studi Literatur

Pada tahap ini penulis melakukan pengumpulan fakta-fakta terkait dengan serangan Bruteforce

2. Tahap Analisis Lingkungan Penelitian Tahap ini adalah tahap dimana peneliti melakukan analisis terkait lingkungan penelitian, yaitu Ubuntu server.

3. Tahap Pengujian Sebelum Implementasi Fail2ban

Tahap ini adalah tahap dimana dilakukan nya serangan Bruteforce terhadap target yang sudah ditentukan yang belum di implementasi Fail2ban. Fail2ban bekerja dengan cara merubah aturan konfigurasi firewall dengan konfigurasi yang berada di Fail2ban itu sendiri, ketika Fail2ban berjalan, ia akan mengambil alih fungsi firewall yang berada di server (Ellingwood [2]).

4. Implementasi Fail2ban

Tahap ini adalah tahap pengimplementasian Fail2ban sebagai 
bentuk solusi dari pencegahan serangan Bruteforce.

5. Konfigurasi Blocklist.de

Tahap ini adalah tahap dimana web reporting di konfigurasi dengan mengisi data dari server yang di implementasi Fail2ban

6. Tahap Pengujian Setelah Implementasi Fail2ban

Tahap ini adalah tahap dimana dilakukan nya pengujian yang sama dengan tahap sebelumnya dengan target yang sudah di implementasi Fail2ban.

7. Analisis Report Blocklist.de Tahap ini adalah tahap dimana menganalisa hasil report yang diterima oleh Blocklist.de dari Ubuntu Server.

\section{IMPLEMENTASI DAN PENGUJIAN}

\subsection{Instalasi Fail2ban}

Fail2ban berfungsi sebagai monitor jumlah kegagalan login ssh di server, yang selanjutnya ip akan diblokir. Dalam kasus ini Fail2ban menangani serangan bruteforce, untuk itu diperlukan beberapa tahap dalam konfigurasi Fail2ban.

1. Update Repository Package

Untuk dapat melakukan instalasi Fail2ban, diperlukan update repository dikarenakan paket Fail2ban tidak tersedia untuk repository default. Untuk update repository ketik perintah, sudo apt-get update.

\section{Fail2ban Package Downloading}

Setelah mendapatkan paket repository terbaru, langkah selanjutnya adalah mengunduh Fail2ban, dan secara otomatis Fail2ban akan terpasang pada Ubuntu server, dengan mengetikan perintah, sudo apt-get install fail2ban.

\section{Fail2ban Config File Downloading}

Setelah mendapatkan paket Fail2ban. Langkah selanjutnya adalah dengan mengunduh debian configuration file yang berada di situs blocklist.de. Configuration file ini berisi pengaturan - pengaturan servis fail2ban. Untuk mendapatkan Configuration file ketik perintah, sudo wget http://www.blocklist.de/downloads/fail2ban.con fig.tar.gz

\section{Fail2ban Config File Extraction}

Langkah selanjutnya adalah dengan melakukan extraction pada configuration file tersebut, agar file dapat digunakan oleh aplikasi Fail2ban. Untuk melakukan extraction ketik perintah, sudo tar $-x z v f$ fail2ban.config.tar.gz.

\section{Fail2ban Config File Replacement}

Setelah melakukan extraction, config file tersebut harus dipindahkan kedalam folder 
dimana fail2ban tersebut berada, hal ini diperlukan untuk mempermudah fail2ban melakukan logging.

\section{Konfigurasi Blocklist.de}

Blocklist.de web yang menyediakan layanan fail2ban reporting. Tujuan digunakan nya blocklist.de adalah sebagai dial-up sender untuk selanjutnya mengirim hasil report beserta detail nya ke email admin yang sebelumnya terdaftar di blocklist.de. Setelah terdaftar di blocklist.de, admin akan diberikan 2 buah email yang berperan sebagai sender dan destination mail. Selanjutnya adalah dengan mendaftarkan server yang digunakan dengan mengisi nama server, alamat IP server, sender mail, dan juga time-zone, dimana alamat IP server adalah alamat IP public dari server yang akan digunakan.

\section{Konfigurasi Jail.conf}

Jail.conf adalah file yang berisi konfigurasi konfigurasi Fail2ban, dimana di dalam jail.conf kita bisa memilih jenis servis mana yang akan digunakan dan yang tidak digunakan. Dalam kasus ini penulis menggunakan servis sshiptables dikarenakan percobaan serangan bruteforce ini melalui port. enabled port

filter

action maxretry $=6$

\section{menyafakan bahwa fail2ban services di port ssh dijalankan} port yang dipakai oleh fail2ban services

service yang digunakan oleh aksi fail2ban

-action_mwl adalah aksi yang mampu mengirimkan log file ke blocklist.de baias maksimal kegagalan login

Gambar 1

Jail.conf

Bisa terlihat dari Gambar 1 bahwa maksimal percobaan login yang dilakukan oleh penyerang adalah $10 \mathrm{kali}$, jika melebihi $10 \mathrm{kali}$ maka sistem akan memutuskan koneksi antara penyerang dan server, dan setiap percobaan login gagal akan dimasukkan kedalam sebuah log yang terletak di direktori /var/log/auth.log .
Setelah semua informasi telah dimasukkan kedalam log maka sistem akan mengirimkan sebuah report yang terkait dengan kegiatan penyerangan dengan alamat pengirim fail2ban[at]dyn.blocklist.de dan alamat tujuan fail2ban[at]blocklist.de.

Hal yang selanjutnya dilakukan adalah memilih aksi yang dilakukan oleh fail2ban jika terjadi penyerangan. Ada 3 jenis aksi yang 
terdapat di dalam jail.conf, Action, Action_mw, dan Action_mwl . Dalam kasus ini penulis memilih aksi Action_mwl, dikarenakan Action_mwl mempunyai kemampuan mengirim email ke alamat yang dituju serta dapat menyimpan semua kegiatan login kedalam sebuah log file .

\section{Starting and Checking Fail2ban Services} Starting and Checking Fail2ban Service perlu dilakukan untuk memastikan bahwa Fail2ban berfungsi dengan baik. Untuk melakukan Starting ketik perintah sudo service fail2ban start.

Setelah melakukan Starting, langkah selanjutnya adalah melakukan Checking untuk mengetahui bahwa Fail2ban telah benar benar berjalan. Untuk melakukan Checking ketik perintah sudo service fail2ban status. Bisa dilihat dari Gambar 2 bahwa Fail2ban sudah berjalan dengan status already running.

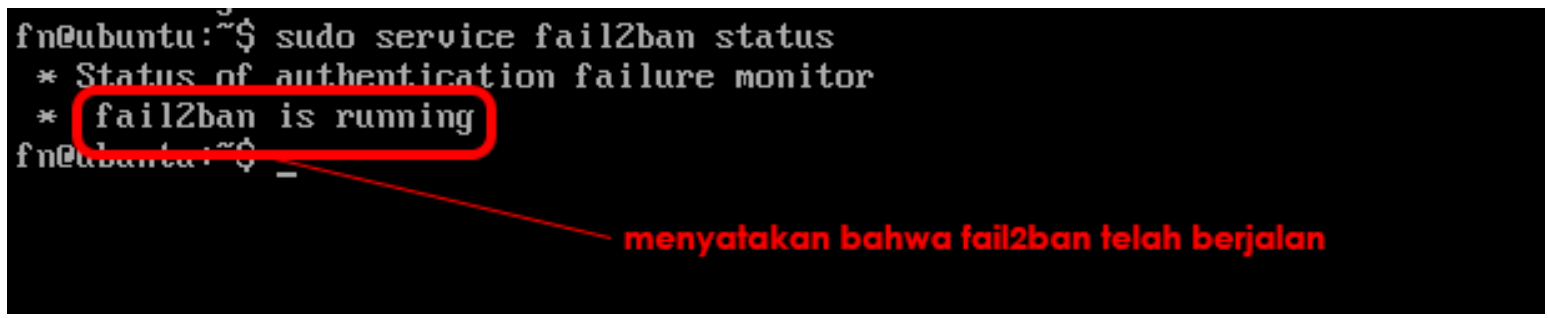

Gambar 2

Starting

\subsection{Pengujian Setelah Implementasi} Fail2ban

Tahap pengujian ini adalah tahap pengujian untuk melihat dampak serangan bruteforce setelah implementasi faizban. Penyerang menggunakan tools yang sama dengan pengujian sebelumnya yaitu dengan menggunakan medusa, dengan alamat ip target 192.168.68.128, berbeda dengan alamat ip target sebelumnya dikarenakan ip Ubuntu server yang digunakan bersifat dinamis. Perintah yang digunakan oleh penyerang pun sama seperti tahap pengujian sebelumnya yaitu, medusa $-h$ 192.168.68.128 $\begin{array}{lllll}-n & 22 & -U & \text { /root/userlist.txt } & -P\end{array}$ /root/password.txt-M ssh . 


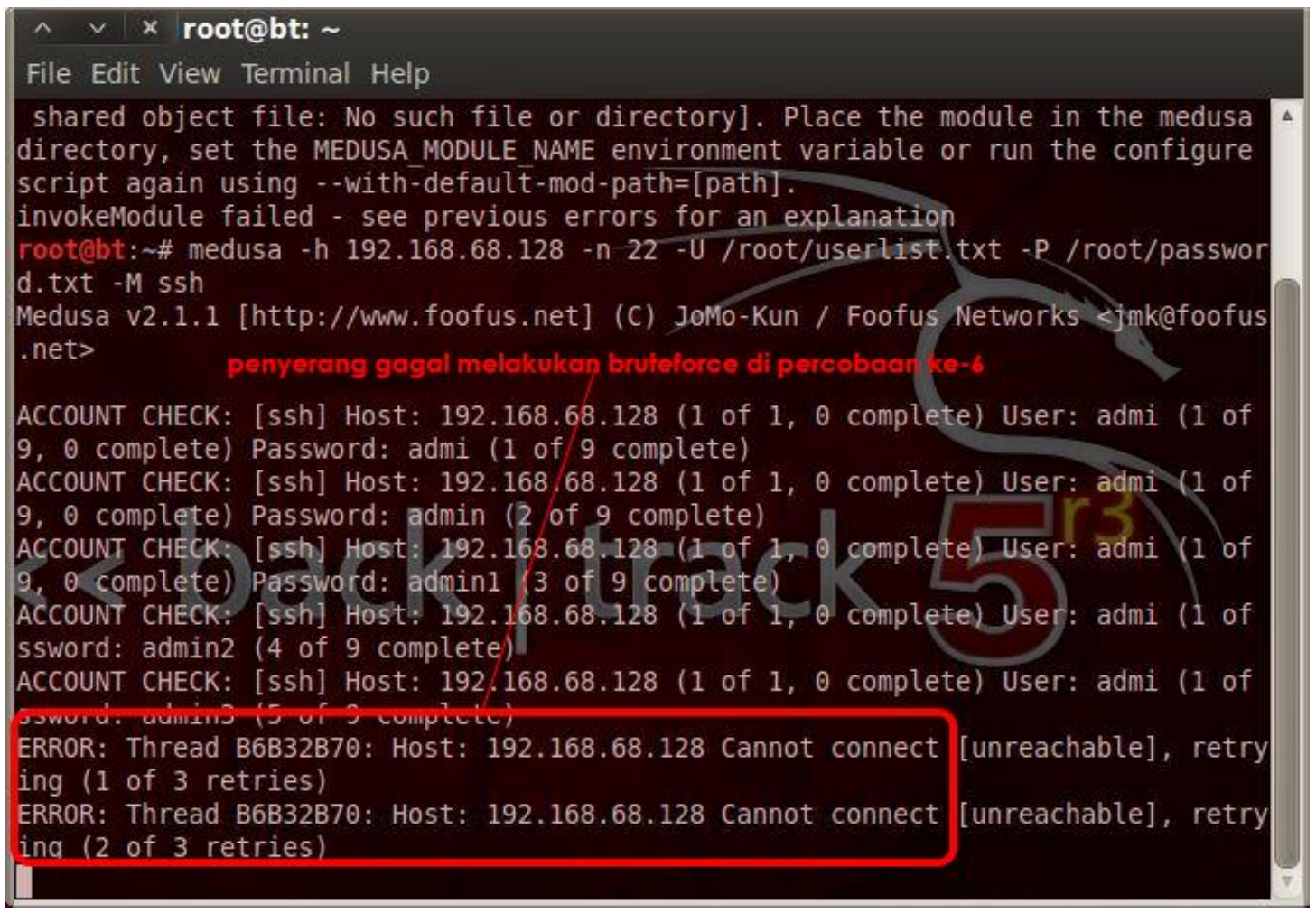

Gambar 3

Pengujian setelah impelemntasi

Terlihat dari Gambar 3 bahwa penyerang tidak berhasil melakukan percobaan login yang keenam kali, dimana target otomatis memutuskan koneksi antara penyerang dan sistem. Pemutusan koneksi ini dilakukan oleh fail2ban yang terpasang di sistem target dimana penyerang hanya bisa melakukan percobaan login sebanyak 6 kali percobaan. Pengaturan terkait dengan maksimal percobaan login sebanyak 6 kali ini disimpan di dalam jail.conf dimana sebelumnya sudah dikonfigurasi. Dengan Action_mwl yang sudah ditetapkan sebelumnya sebagai aksi fail2ban, maka setiap percobaan gagal login akan disimpan kedalam sebuah log file yang terletak di direktori /var/log/auth.log. Untuk melihat log file ketik perintah, nano /var/log/auth.log. 


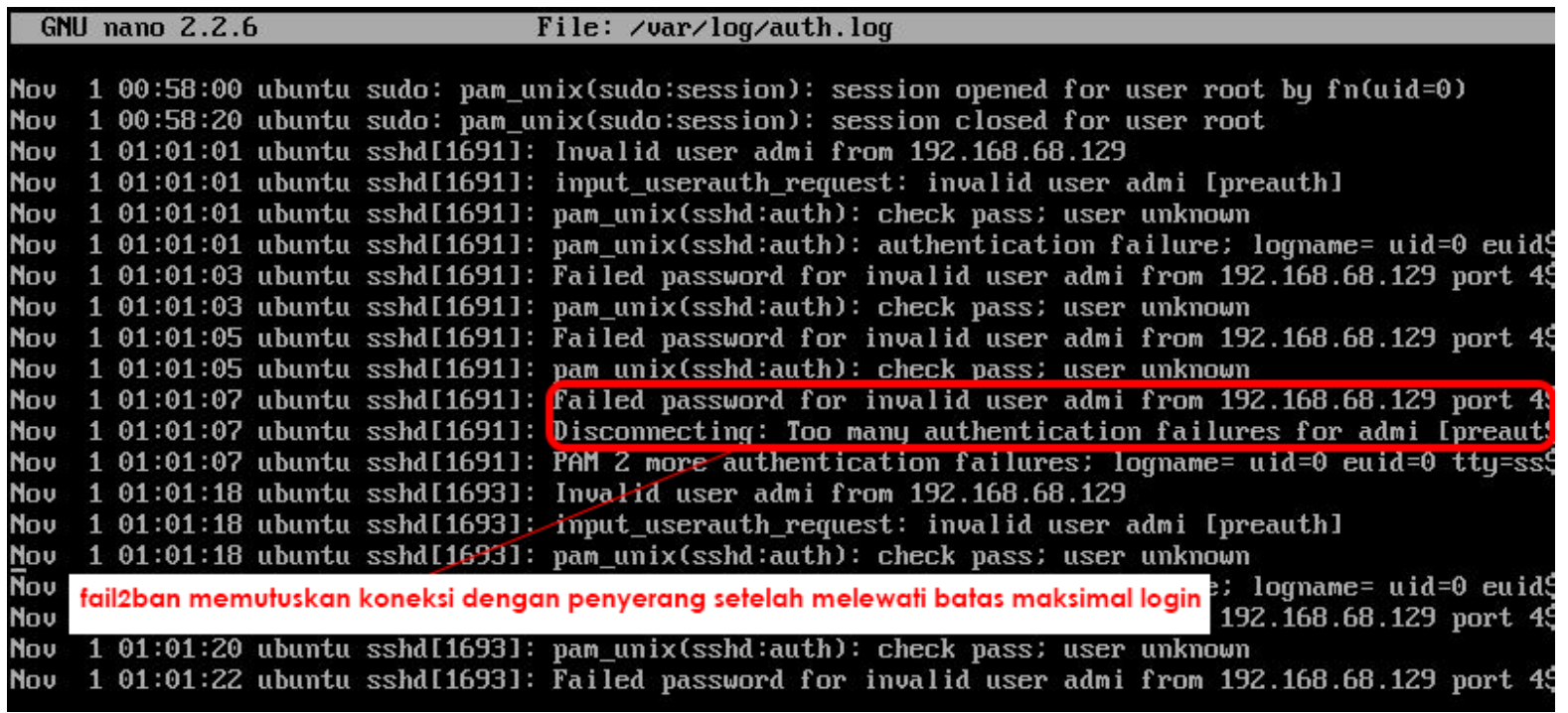

\section{Gambar 4}

Log file

Bisa terlihat dari Gambar 4 di atas dimana ada sebuah percobaan login yang dilakukan oleh alamat ip 192.168.68.129 dimana alamat ip tersebut adalah alamat ip dari penyerang, dan terlihat bahwa penyerang melakukan percobaan login sebanyak 5 kali yang dinyatakan gagal.

Terkait dengan penjelasan sebelumnya bahwa aksi Action_mwl memiliki kemampuan untuk Currently, you have entered 1 Server. mengirimkan laporan penyerangan ke email melalui third-party applications yaitu blocklist.de, maka seharusnya setiap laporan penyerangan akan dikirimkan terlebih dahulu melalui blocklist.de lalu dilanjutkan ke email admin. Laporan penyerangan bisa dilihat melalui website blocklist.de.

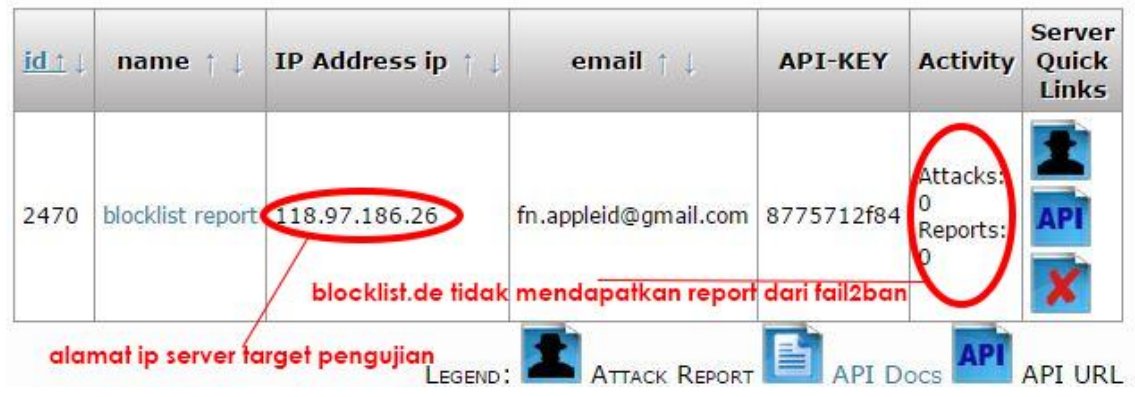

Gambar 5

Bocklist de report 
Bisa terlihat dari Gambar 5 bahwa alamat ip 118.97.186.26 yaitu alamat ip server tidak menerima laporan penyerangan ataupun laporan lainnya yang terkait dengan kegiatan di server.

\section{KESIMPULAN}

Kesimpulan dari penelitian ini solusi yang ditawarkan oleh penulis untuk melakukan implementasi fail2ban pada Ubuntu server untuk mencegah serangan bruteforce.

1. Implementasi fail2ban pada Ubuntu server terbukti dapat mencegah serangan bruteforce dan memblokir alamat ip dari penyerang tersebut kedalam daftar blacklist.
2. Fail2ban tidak dapat memberikan report kepada administrator melalui web blocklist.de dan email administrator.

\section{DAFTAR PUSTAKA}

[1] Canavan, J. E, "Fundamentals of Network Security", Artech House, 2001

[2] Ellingwood, Justin "How Fail2ban Works to Protect Services on Linux Server", https://www.digitalocean.com/community/ tutorials/how-fail2ban-works-to-protectservices-on-a-linux-server, Mei 2014 